\title{
The 2017 JPED Editor Choice Awards
}

Published online: 12 January 2018

(c) ASM International 2018

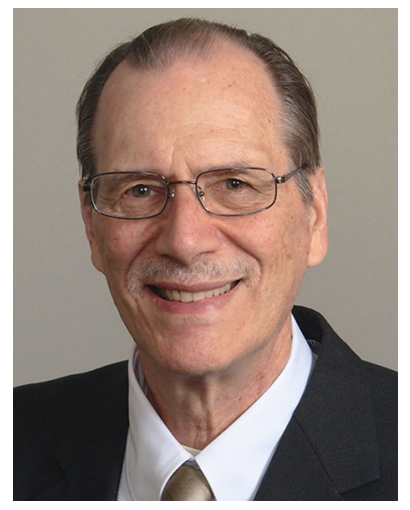

Selection of the annual JPED Editor Choice Awards for 2017 have been made and are given below. Information about how award selections are made can be found in the December 2015 issue of this Journal.

I. Saenko, O.Fabrichnaya, A.Udovsky, New Thermodynamic Assessment of the Fe-Y System, Phase Equilib. Diff., 2017, 38(5), p 684-699.

S-M. Liang, R. Schmid-Fetzer, Evaluation of Calphad Approach and Empirical Rules on the Phase Stability of Multi-principal Element Alloys, Phase Equilib. Diff., 2017, 38(4), p 369-381.

T. Hidayat, D. Shishin, S.A. Decterov, E. Jak, Experimental Study and Thermodynamic Re-optimization of the $\mathrm{FeO}-\mathrm{Fe}_{2} \mathrm{O}_{3}-\mathrm{SiO}_{2}$ System, Phase Equilib. Diff., 2017, 38(4), p 477-492.

C. Zhang, F. Zhang, K. Jin, H. Bei, S. Chen, W. Cao, J. Zhu, D. Lv, Understanding of the Elemental Diffusion
Behavior in Concentrated Solid Solution Alloys, Phase Equilib. Diff., 2017, 38(4), p 434-444

B. Konar, J.Kim, I-H. Jung, Critical Systematic Evaluation and Thermodynamic Optimization of the Fe-RE System: RE = Gd, Tb, Dy, Ho, Er, Tm, Lu, and Y, Phase Equilib. Diff., 2017, 38(4), p 509-542

Letters confirming the Awards have been sent via email to corresponding authors of each paper (underlined above). Co-authors can receive a copy of the letter from their corresponding author or by sending a request to jemorral@gmail.com.

In addition to the award, papers are given "Free Access" via the Springer/JPED website http://www. springer.com/materials/journal/11669 or SpringerLink. Free access means that papers can be viewed 24/7 worldwide by anyone with an internet connection. Normally there is a US\$ 3000 charge for "Free Access," but for papers that have won this award the benefit is free.

As in previous years it was difficult to pare the "short list" of 12 papers down to the allowed number of five. We at JPED thank all authors who have sent us their fine work and heartily congratulate all who received an Editor Choice Award for 2017. On this occasion, we wish to thank also our valued reviewers for their efforts to make JPED a quality publication.

John Morral

Editor-in-Chief

Journal of Phase Equilibria and Diffusion 